Cite this: RSC Advances, 2013, 3, 4145

Received 26th October 2012,

Accepted 22nd January 2013

DOI: $10.1039 / \mathrm{c} 3 \mathrm{ra00121k}$

www.rsc.org/advances

\section{Improved electromagnetic interference shielding effectiveness of light weight carbon foam by ferrocene accumulation}

\author{
Rajeev Kumar, Sanjay R. Dhakate, ${ }^{*}$ Parveen Saini and Rakesh B. Mathur
}

The influence of nanosized iron particles (NSIP) derived from an organometallic compound, i.e. ferrocene, on the properties of light weight carbon foam (CF) derived from coal tar pitch was investigated. It was observed that NSIP acts as a catalyst, resulting in an improved degree of graphitization of CF with increasing NSIP content and hence, higher electrical and thermal conductivity values. The higher value of conductivity has a positive effect on the electromagnetic interference (EMI) shielding effectiveness (SE) of the CF. The EMI SE increased with increasing NSIP content in CF. The specific SE of the light weight CF was $130 \mathrm{~dB} \cdot \mathrm{cm}^{3} / \mathrm{g}$ at 10 wt\% of ferrocene in $\mathrm{CF}$, which is the highest value reported so far for CF, particularly at such a low thickness $(2.75 \mathrm{~mm}$ ). Besides, it was thermally stable up to $600{ }^{\circ} \mathrm{C}$ in an oxidizing atmosphere and exhibits high specific thermal conductivity up to $121 \mathrm{~W} \mathrm{~cm}$ $\mathrm{g}^{-1} \mathrm{~m}^{-1} \mathrm{~K}^{-1}$.

\section{Introduction}

The increasing use of wireless devices in the modern technological world and related electromagnetic (EM) radiation is becoming a serious problem that disturbs the stable working conditions of electronic appliances and may do harm to humans. ${ }^{1}$ In high-end technological applications such as in civil and military aerospace vehicles, protection from EM radiation, as well as regulation of thermal heating of electronic power systems, is necessary to protect them from any form of damage. In particular, light weight shielding and structural materials are needed to mitigate EM interference (EMI) from electronic systems and to protect humans from the hazards of space radiation e.g. aerospace vehicles, especially in the $8-12.4 \mathrm{GHz}$ frequency region (X-band). ${ }^{2,3}$ The traditional radiation shielding materials have disadvantages like high density, corrosion tendency and difficulty in processing. Practically, an effective EMI shielding material which is light weight is an important requirement in aerospace transportation vehicles and space structures. ${ }^{4}$ The shielding effectiveness (SE)

Division of Materials Physics and Engineering, CSIR-National Physical Laboratory, Dr K. S. Krishnan Marg, New Delhi-110012, India.

E-mail:dhakate@mail.nplindia.org value should be $>-50 \mathrm{~dB}$ in the $\mathrm{X}$-band. ${ }^{5}$ The EMI attenuation offered by a shield depends upon three mechanisms; reflection of the incident radiation from the shield's face, absorption of the unreflected radiation as it passes through the shield and rereflection i.e. multiple reflections of the waves at various interfaces within the shield. The multiple reflections require the presence of large surface areas; however, it is negligible in the case of highly absorbing or electrically conducting thick shield materials.

Carbon foam (CF) is a sponge-like rigid high performance engineering material in which carbon ligaments are interconnected to each other. ${ }^{6,7}$ Recently, it has attracted lot of attention owing to its outstanding properties such as low density, large surface area with an open cell wall structure, and good thermal and mechanical stability. ${ }^{8-10}$ However, there are few studies available in the literature on the SE of CF as an EMI shielding material, but in these studies $\mathrm{CF}$ is heat treated at lower temperature (600-800 ${ }^{\circ} \mathrm{C}$ ) and the EMI shielding effectiveness in the frequency $1-4.5 \mathrm{GHz}$ is dominated by adsorption.

Yang et al. ${ }^{11}$ developed a CF from mesophase pitch by a foaming technique and these foams were heat treated at a temperature between $400-800{ }^{\circ} \mathrm{C}$. It is reported that carbon foam heat treated at 600 and $700{ }^{\circ} \mathrm{C}$ exhibits better microwave absorption (reflection loss $-10 \mathrm{~dB}$ ). Fang et al. $^{12}$ reported the numerical prediction and experimental validation of $\mathrm{CF}$ as a microwave absorber. The $\mathrm{CF}$ is fabricated by a traditional technique using a polymer foam replication method and it is heat treated at 700, 750 and $800{ }^{\circ} \mathrm{C}$ and displayed a reflection coefficient in the range of -8 to $-10 \mathrm{~dB}$ for $20 \mathrm{~mm}$ thick foam. Fang et $a l .{ }^{13}$ studied the EM characteristics of CF with different pore size and their pulverized powders are measured by a resonant cavity perturbation technique in the 2 to $4.5 \mathrm{GHz}$ frequency range. The CF has a dielectric loss several times larger than the corresponding pulverized powder. The CF shows a magnetic loss, while no magnetic loss can be observed from the corresponding pulverized powders. This demonstrates that microstructure modification is an effective way to modulate the electromagnetic properties of CF. Moglie et al. ${ }^{14}$ investigated the EM shielding performance of $\mathrm{CF}$ using the nested reverberation chamber method in the band 1-4 GHz range, which is the frequency range 
of most cellular phones and microwave ovens and found a maximum attenuation of $-60 \mathrm{~dB}$.

In the present investigation, an effort has been made to develop CF with improved SE, thermal conductivity and thermal stability, which is required in aerospace transportation vehicles and space structures. The foam is developed by the sacrificial template technique from coal tar pitch (CTP). Initially, the CTP was modified by incorporating a nanosized organometallic compound (ferrocene) with different weight fractions in CTP and these foams were heat treated at up to $2500{ }^{\circ} \mathrm{C}$ in an inert atmosphere. The effect of nanosized ferrocene is ascertained by characterizing the carbon foam by X-ray diffraction, electrical conductivity, thermal conductivity, thermal stability in oxidizing atmosphere and electromagnetic interference shielding effectiveness.

\section{Experimental and characterization}

\subsection{Preparation of $\mathbf{C F}$}

The CF was prepared by the sacrificial template technique in which the polyurethane (PU) foam (density $0.030 \mathrm{~g} \mathrm{~cm}^{-3}$ and average pore size $0.45 \mathrm{~mm}$ ) was used as the template. The PU foam was impregnated by a slurry of CTP mixed with different proportions (viz. 0, 2, 5 and $10 \mathrm{wt} \%$ ) of nanosized ferrocene using the vacuum infiltration technique. The CTP-ferrocene mixture was prepared by ball milling, followed by heat treatment inside a stainless steel reactor at $400{ }^{\circ} \mathrm{C}$ for $25 \mathrm{~h}$ to generate mesophase content in the mixture. Then the mixture was ground by ball milling in a tungsten carbide jar for about 5-6 h to get the particle size of the mixture less than $30 \mu \mathrm{m}$ so that these particles can easily penetrate inside the cells of PU foam. The above mixture was converted into a water based slurry (with $3 \%$ polyvinyl alcohol) and it was impregnated inside the pores of the PU foam template by the vacuum infiltration technique. Finally, the impregnated PU foam was converted into CF by a series of heat treatments in air as well as in an inert atmosphere at up to $2500{ }^{\circ} \mathrm{C}$. ${ }^{15}$

\subsection{Characterization of $\mathbf{C F}$}

The morphology of the CF was observed by scanning electron microscopy (SEM model LEO 440). The electrical conductivity of the foam was measured by a four-probe technique using a Keithley 224 programmable current source and a Keithley 197A auto ranging microvolt DMM. The thermal conductivity of $\mathrm{CF}$ was measured by the laser flash method with a xenon laser as the source in a Thermo Flash Line 2003 instrument (Anter Corporation, USA). Test samples of size $12.7 \mathrm{~mm} \times 12.7 \mathrm{~mm} \times$ $3 \mathrm{~mm}$ were prepared and the thermal diffusivity and specific heat of each sample were measured at $25^{\circ} \mathrm{C}$. The thermal conductivity was then calculated from the equation, $\alpha=k / \rho C_{\mathrm{p}}$, where $\alpha$ is the thermal diffusivity, $k$ is thermal conductivity, $C_{\mathrm{p}}$ is the specific heat and $\rho$ is density of the CF. The crystallinity parameter of CF was determined by X-ray diffraction (XRD, D-8 Advanced Bruker diffractometer) using a Cu-K $\alpha$ radiation $(\lambda=1.5418 \AA)$ spectrometer. The (110) reflection was used to calculate average crystallite width $\left(L_{\mathrm{a}}\right)$ by the Scherrer equation, ${ }^{16} L_{\mathrm{a}}=k \lambda / \beta \cos \theta$, where $k$ is the Scherrer constant $=1.84$.

The (002) reflection is used to obtain average crystallite height $\left(L_{\mathrm{c}}\right), L_{\mathrm{c}}=k \lambda / \beta \cos \theta$, where $k=0.9$ is the Scherrer constant, $\beta$ is the corrected FWHM value in radians.

The degree of graphitization $(g)$ was calculated using the expression:

$$
g(\%)=\left(0.3440-d_{(002)} / 0.3440-0.3354\right) \times 100
$$

where 0.3440 is the interlayer spacing of turbostratic graphite (nm), 0.3354 is the interlayer spacing of the ideal graphite crystallite and $d_{(002)}$ is the interlayer spacing calculated from the XRD (nm) of CF.

Electromagnetic interference (EMI) shielding effectiveness was measured by waveguide using a vector network analyzer (VNA, E8263BAgilent Technologies). The rectangular samples of thickness $2.70-2.75 \mathrm{~mm}$ were placed inside the cavity of the sample holder which matches the internal dimensions of the X-band (8.212.4 GHz) waveguide. The sample holder was placed between the flanges of the waveguide connected between the two ports of the VNA. A full two port calibration was performed using quarter wavelength offset and terminations and keeping the input power level at $-5.0 \mathrm{dBm}$.

\section{Results and discussion}

Table 1 shows the different properties of CF heat treated at 2500 ${ }^{\circ} \mathrm{C}$. The CTP is a material consisting of different molecular weight aliphatic and aromatic hydrocarbons and a small amount of oxygen and sulfur containing hydrocarbon. These sulfur and oxygen containing hydrocarbons exhibit higher reactivity than other hydrocarbons because of their higher electronegativity and can easily react with ferrocene or its pyrolytic product iron atom cluster. Initially, in the mixture of ferrocene and CTP, the nanosized iron from the ferrocene reacts with sulfur and oxygen (Fig. 1, scheme I) to form iron sulfide (FeS) and iron oxide (FeO) with increasing carbonization temperature from 500 to $700{ }^{\circ} \mathrm{C}$. During the pyrolysis, the decomposition of ferrocene results in the formation of elemental nanosized iron particles. However, during the heat treatment, there is a possibility of nanosized iron cluster

Table 1 Properties of carbon foam with increasing ferrocene content

\begin{tabular}{|c|c|c|c|c|c|c|c|}
\hline $\begin{array}{l}\text { Ferrocene content } \\
\text { (wt\% in pitch) }\end{array}$ & $\begin{array}{l}\text { Density } \\
\left(\mathrm{g} \mathrm{cm}^{-3}\right)\end{array}$ & $\begin{array}{l}\text { Electrical conductivity } \\
\left(\mathrm{S} \mathrm{cm}^{-1}\right)\end{array}$ & $d_{002}(\mathrm{~nm})$ & $g(\%)$ & $L_{\mathrm{c}}(\mathrm{nm})$ & $L_{\mathrm{a}}(\mathrm{nm})$ & $\begin{array}{l}\text { Thermal conductivity } \\
\left(\mathrm{W} \mathrm{m} \mathrm{m}^{-1} \mathrm{~K}^{-1}\right)\end{array}$ \\
\hline 0 & 0.52 & 80 & 0.3396 & 51 & 8.4 & 11.5 & 48 \\
\hline 2 & 0.55 & 86 & 0.3387 & 61 & 8.7 & 12.9 & 59.3 \\
\hline 5 & 0.59 & 96 & 0.3380 & 69.7 & 10.1 & 17.1 & 65.8 \\
\hline 10 & 0.62 & 110 & 0.3375 & 75.6 & 13.1 & 21.7 & 75 \\
\hline
\end{tabular}




$$
\begin{aligned}
& \left(\mathrm{C}_{5} \mathrm{H}_{5}\right)_{2} \mathrm{Fe}+\text { coal tar pitch } \stackrel{>500-700^{\circ} \mathrm{C}}{\longrightarrow} \text { Fe-O or Fe-S -----I } \\
& \mathrm{Fe}-\mathrm{O} \text { or } \mathrm{Fe}-\mathrm{S}+\mathrm{C} \stackrel{>700-900^{\circ} \mathrm{C}}{\longrightarrow} \mathrm{Fe}-\mathrm{C} \quad \text {-- -------II }
\end{aligned}
$$

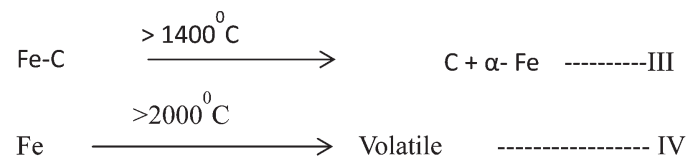

Fig. 1 The schematic representation of the phase transition reaction of coal tar pitch and ferrocene at different heat treatment temperatures.

formation due to migration. ${ }^{17}$ The life time of the nanosized iron clusters is limited because of their sulfidation ${ }^{18}$ due to poisoning by sulfur and oxidation, which result in the formation of iron sulfide and oxide. It is well known that carbon is a reducing agent which can react with $\mathrm{FeS}$ and $\mathrm{FeO}$ compounds at $700-900{ }^{\circ} \mathrm{C}$ and transform into iron carbide (Fig. 1, scheme II), which subsequently converted into $\alpha$-Fe content and carbon above $1400{ }^{\circ} \mathrm{C}$ (Fig. 1, scheme III). Above $2000{ }^{\circ} \mathrm{C}$, there is evaporation of iron from the CF (scheme IV).

It is important to note that the amount of graphitic carbon generated in the $\mathrm{CF}$ (due to the catalytic activity of iron) depends upon the amount of ferrocene incorporated into the CTP and so does the properties of the resultant $\mathrm{CF}$.

The bulk density of CF $\left(0.52 \mathrm{~g} \mathrm{~cm}^{-3}\right)$ increases with increasing nanosize ferrocene content of the starting CTP and becomes 0.55 , 0.59 and $0.62 \mathrm{~g} \mathrm{~cm}^{-3}$ for 2,5 and $10 \mathrm{wt} \%$ respectively (Table 1). The increase in bulk density is closely related to the change in the structure of carbon in carbon foam and this is verified by X-ray diffraction (Fig. 2). It is seen that the interlayer spacing $\left(d_{002}\right)$ decreases with increasing content of ferrocene i.e. from $0.3396 \mathrm{~nm}$ in the absence of ferrocene to $0.3375 \mathrm{~nm}$ for $10 \mathrm{wt} \%$ of ferrocene loading. The decrease in the interlayer spacing is due to the ordering of graphene layers and as a consequence, compaction between layers resulting in an increase in bulk density. In other words, increasing content of ferrocene decreases the interlayer spacing and increases the degree of graphitization (Table 1). The electrical conductivity of $\mathrm{CF}$ increases with increasing content of ferrocene i.e. from $80 \mathrm{~S} \mathrm{~cm}^{-1}$ in the absence of ferrocene to $110 \mathrm{~S}$ $\mathrm{cm}^{-1}$ for $10 \mathrm{wt} \%$ of ferrocene loading. The increase in conductivity is due to the increase in the conduction path of electrons, which is directly proportional to crystallite size and degree of graphitization. ${ }^{19}$ The crystallite size and degree of graphitization of carbon foam increase with increasing content of ferrocene in the CTP.

The crystallite width and height increase with the content of ferrocene from $11.5 \mathrm{~nm}\left(L_{\mathrm{a}}\right)$ and $8.4 \mathrm{~nm}\left(L_{\mathrm{c}}\right)$ in the absence of ferrocene to $21.7 \mathrm{~nm}$ to $13.1 \mathrm{~nm}$ for $10 \mathrm{wt} \%$ of ferrocene loading. The degree of graphitization $(g)$ depends upon the interlayer spacing between the graphene layers in the resultant material; it increases from $51 \%$ in the absence of ferrocene to $75.6 \%$ for 10 $\mathrm{wt} \%$ of ferrocene loading. This resulted in the improvement of the stacking order of graphene layers. The thermal conductivity is dominated by lattice vibration and hence, the mean free path of electrons, causing an increase in the thermal conductivity of the carbon foam. With increasing content of ferrocene in CTP, the lattice parameters $L_{\mathrm{a}}$ and $L_{\mathrm{c}}$ increase due to catalytic graphitization. The thermal conductivity is also one of the important criteria for quick heat dissipation in carbon foam used in civil and military aerospace vehicles to protect them from thermal heating of electronic power systems. The higher the thermal conductivity, the quicker the heat dissipation in an electronic system, which does not alter the functioning in aerospace vehicles. The thermal conductivity of carbon foam is $48 \mathrm{~W} \mathrm{~m}^{-1} \mathrm{~K}^{-1}$ in the absence of ferrocene to $75 \mathrm{~W} \mathrm{~m}^{-1} \mathrm{~K}^{-1}$ for $10 \mathrm{wt} \%$ of ferrocene loading. The extent of the increase depends upon the crystallite growth;

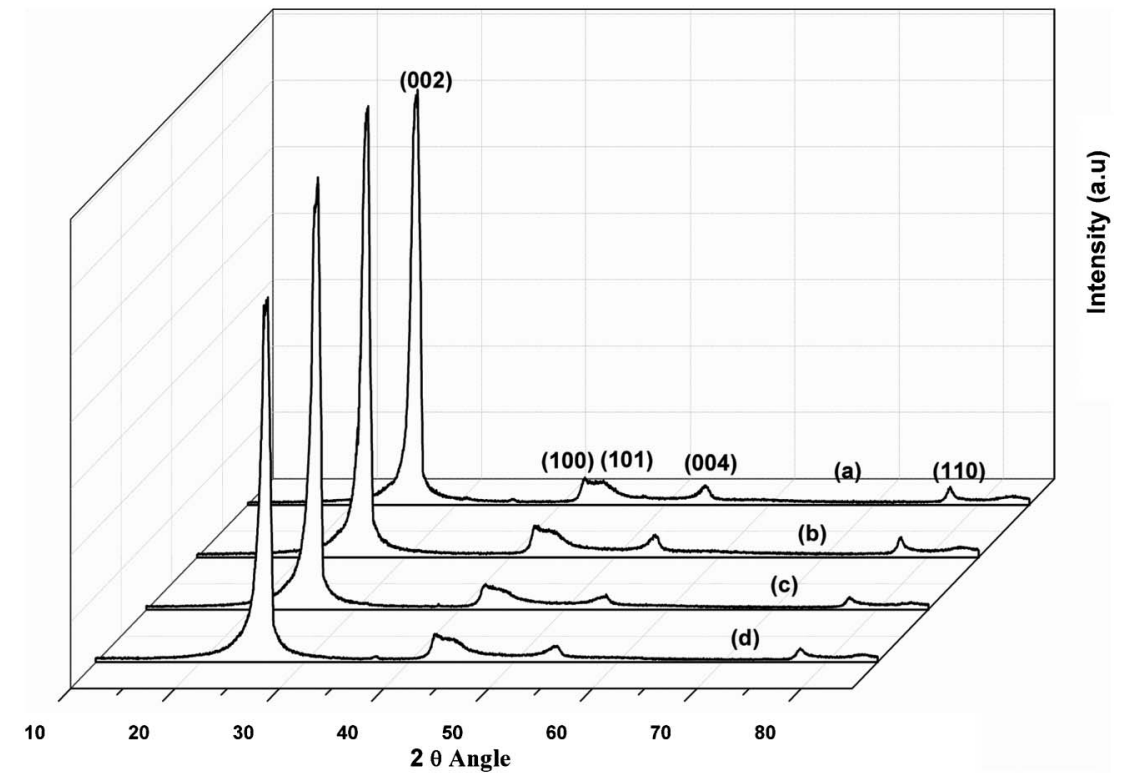

Fig. 2 XRD of carbon foam with ferrocene content (a) absence of ferrocene, (b) 2 wt\% ferrocene, (c) 5 wt $\%$ ferrocene and (d) 10 wt $\%$ ferrocene. 

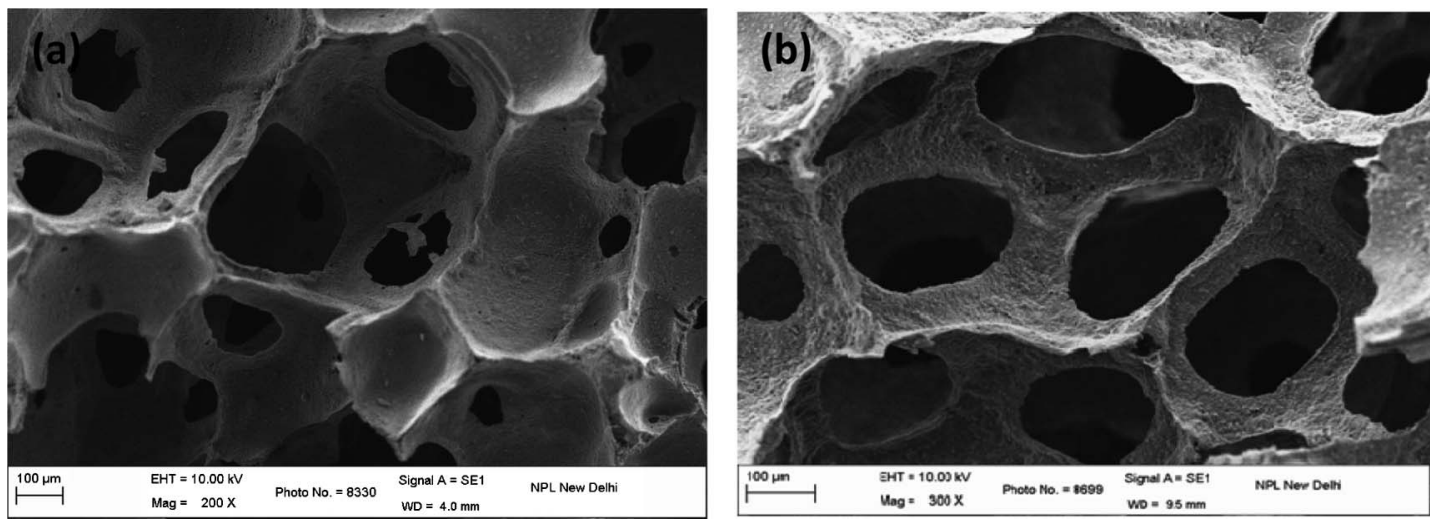

Fig. 3 SEM micrograph of carbon foam derived from coal tar pitch (a) absence of ferrocene (b) 10 wt $\%$ of ferrocene loading, heat treated at $2500{ }^{\circ} \mathrm{C}$.

therefore, with the increasing ferrocene content in the carbon foam, crystallite width increases and hence the thermal conductivity increases.

Fig. 3 shows the SEM micrograph of CF heat treated at $2500{ }^{\circ} \mathrm{C}$ derived from CTP which revealed that pores are uniformly distributed although some pores walls in the micrographs are broken during sample preparation for SEM analysis. The pore walls are called ligaments, which are interconnected to each other and are responsible for the overall properties of the carbon foam. It can be seen that $\mathrm{CF}$ without any addition of ferrocene in the CTP (Fig. 3a) appears less bright compared to CF derived from the ferrocene addition (Fig. 3b), which is due to the more conductive nature.

The EMI shielding effectiveness (SE) of a material is the ability to attenuate EM radiation that can be expressed in terms of the ratio of incoming (incident) and outgoing (transmitted) power. The EMI attenuation offered by a shield may depend on three mechanisms: reflection of the wave from the front face of the shield, absorption of the wave as it passes through the shield's thickness and multiple reflections of the waves at various interfaces. $^{20}$ Therefore, the SE of EMI shielding materials is determined by three losses: reflection loss (R), absorption loss (A) and multiple reflection loss (M), and is defined as follows:

$$
\mathrm{SE}(\mathrm{dB})=\mathrm{SE}_{\mathrm{R}}+\mathrm{SE}_{\mathrm{A}}+\mathrm{SE}_{\mathrm{M}}
$$

The loss associated with multiple reflections can be ignored $\left(\mathrm{SE}_{\mathrm{M}} \sim 0\right)$ when $\mathrm{SE}$ of the EMI shielding material is more than $-10 \mathrm{~dB} .{ }^{21}$ Hence, $\mathrm{SE}$ can be expressed as $\mathrm{SE}(\mathrm{dB})=\mathrm{SE}_{\mathrm{R}}+\mathrm{SE}_{\mathrm{A}}$.

Fig. 4 shows the variation of the EMI SE of CF with loading of ferrocene in the frequency range of 8.2 to $12.4 \mathrm{GHz}$. It is observed that SE increases with increasing content of ferrocene in the CTP. The SE of CF without ferrocene is $\sim-39 \mathrm{~dB}$, which increases to $\sim-44, \sim-57$ and $\sim-81 \mathrm{~dB}$ for 2,5 , and $10 \mathrm{wt} \%$ of ferrocene loaded sample respectively. It is important to note that in all cases, the $\mathrm{SE}$ is mostly dominated by reflection $\left(\mathrm{SE}_{\mathrm{R}}\right)$ as compared to absorption $\left(\mathrm{SE}_{\mathrm{A}}\right)$. The increase in $\mathrm{SE}_{\mathrm{R}}$ with increasing ferrocene content can be correlated with increasing electrical conductivity. In three cases (Fig. $4 \mathrm{a}, \mathrm{b}$ and $\mathrm{c}$ ), $\mathrm{SE}_{\mathrm{A}}$ is almost the same, while in Fig. $4 \mathrm{~d}$ the value of $\mathrm{SE}_{\mathrm{A}}$ is higher. This is due to the higher content of ferrocene (10 wt\%) in the CF; during heat treatment above a temperature of $2000{ }^{\circ} \mathrm{C}$, the amount of nanosized iron evaporation is higher and results in a higher degree of nanosize porosity. This is attributed to a greater $\mathrm{SE}_{\mathrm{A}}$ in the case of $\mathrm{CF}$ with $10 \mathrm{wt} \%$ ferrocene. According to EM theory, the high frequency EM radiation penetrates only the near surface region of an electrical conductor, which is known as the skin effect. The depth at which the field drops to $1 / \mathrm{e}$ of the incident value is called skin depth $(\delta),{ }^{22}$ which can be expressed as $\delta=\left(2 / \omega_{f} \mu \sigma\right)^{1 / 2}$, where, $\omega_{f}$ is angular frequency, $\mu$ is permeability, and $\sigma$ is electrical conductivity. As explained in the earlier section, with increasing ferrocene content, the degree of catalytic graphitization increases, leading to increases in the electrical conductivity of CF. This is attributed to the higher value of EMI shielding effectiveness and hence, it demonstrates that shielding effectiveness is dominated by electrical conductivity. Consequently, skin depth decreases, making possible a higher level of EMI SE, even for thinner shield materials. Fig. 5 compares the shielding effectiveness of $\mathrm{CF}$ with increasing ferrocene content, displaying an increase in EMI SE from $\sim-39 \mathrm{~dB}$ to $\sim-81 \mathrm{~dB}$ for 0 and $10 \mathrm{wt} \%$ of ferrocene loaded samples, respectively.

Another important quantity which is used here to compare the SE of different materials with CF at comparative thickness values is specific shielding effectiveness (SSE) which is defined as attenuation $(\mathrm{dB})$ per unit density of material. Fig. 6 compares the SSE of different materials in the X-band region (8.2 to 12.4 $\mathrm{GHz}$ ) that have been used recently in different applications. The SSE of solid copper is $-10 \mathrm{~dB} \mathrm{~cm}^{3} \mathrm{~g}^{-1,23}$ which is the lowest value among all other materials reported in Fig. 6. On the other hand, for the CNT-PEEK nanocomposite with $12 \mathrm{wt} \%$ purified multiwalled carbon nanotubes, an SSE value of $-37.3 \mathrm{~dB} \mathrm{~cm}^{3} \mathrm{~g}^{-15}$ is reported. Yang et al. ${ }^{4}$ reported that the SSE is $-33.1 \mathrm{~dB} \mathrm{~cm}^{3} \mathrm{~g}^{-1}$ for a novel carbon nanotube-polystyrene foam composite, which is much higher than that of solid copper. Recently, Yan et al. ${ }^{24}$ reported a light weight porous graphene/polystyrene composite with an SSE of $-64.4 \mathrm{~dB} \mathrm{~cm}^{3} \mathrm{~g}^{-1}$ for $30 \%$ loading of functionalized graphene sheets. In the present work, the SSE value of CF derived from CTP without ferrocene is $-75 \mathrm{~dB} \mathrm{~cm}$ $\mathrm{g}^{-1}$, which further increased to $-130 \mathrm{~dB} \mathrm{~cm}^{3} \mathrm{~g}^{-1}$ with $10 \mathrm{wt} \%$ ferrocene loading in CTP. 

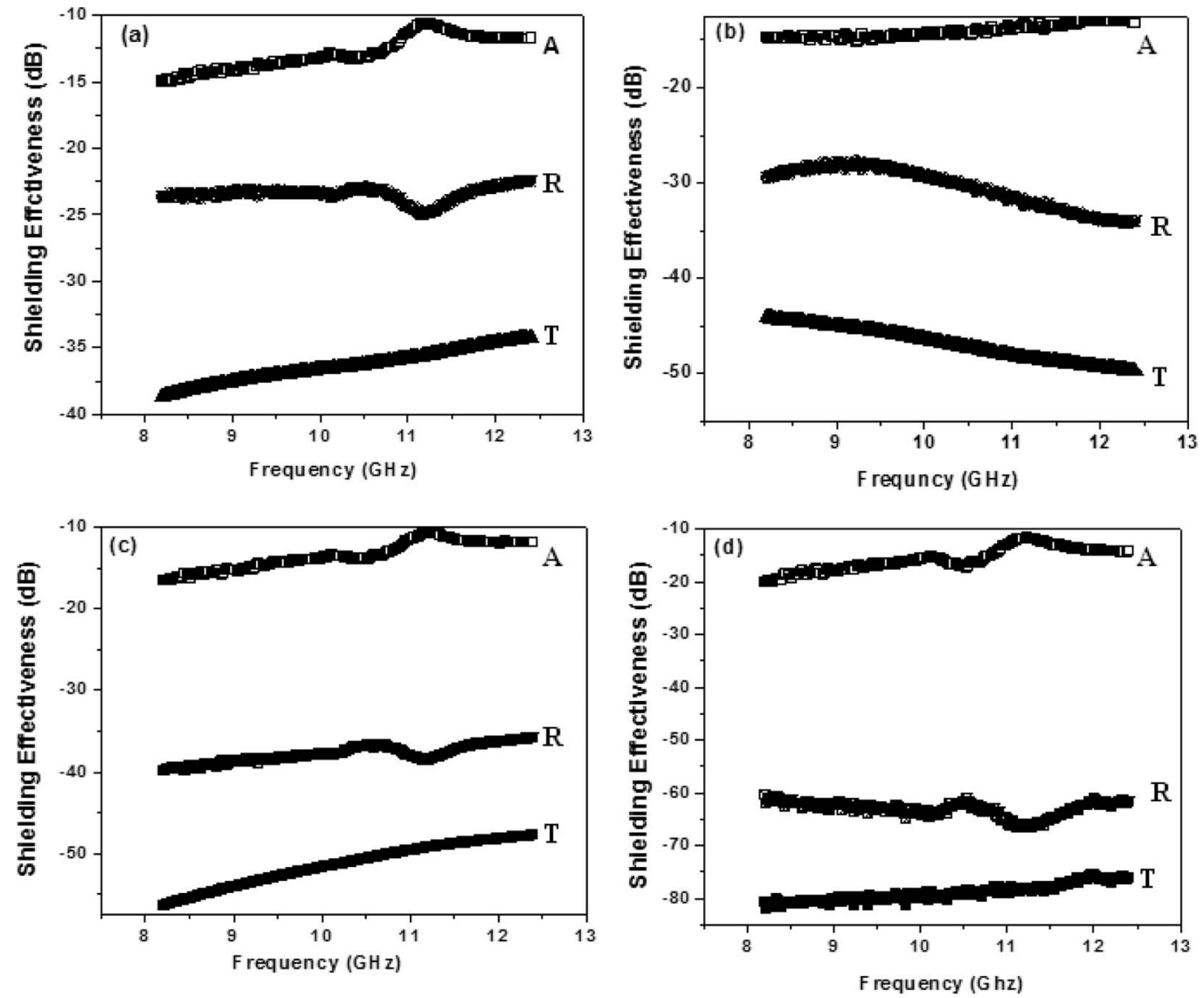

Fig. 4 EMI shielding effectiveness \{A: absorption, R: Reflection and T: Total (Absorption + Reflection)\} over the frequency range of 8.2 to $12.4 \mathrm{GHz}$ for carbon foam with loading of ferrocene in coal tar pitch (a) 0 wt $\%$,(b) 2 wt $\%$ (c) 5 wt $\%$ and (d) 10 wt $\%$.

In the case of $\mathrm{CF}$, the ligaments are conductive graphene planes oriented along the walls of the pores in the foam, giving higher conductivity than bulk carbon. The addition of ferrocene in CTP leads to catalytic graphitization of $\mathrm{CF}$, resulting in an improvement of overall conductivity. The EMI SE and SSE values

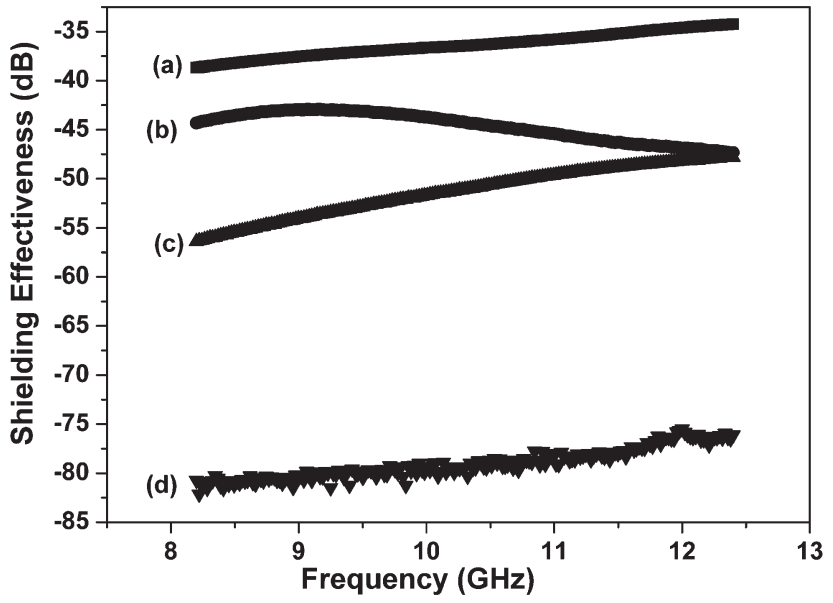

Fig. 5 Effect of ferrocene content on shielding effectiveness of CF (a) 0 wt\%, (b) 2 $w t \%$ (c) $5 w t \%$ and (d) $10 w t \%$ of ferrocene. are $\sim-81 \mathrm{~dB}$ and $-130 \mathrm{~dB} \mathrm{~cm}^{3} \mathrm{~g}^{-1}$ for thick $2.75 \mathrm{~mm} \mathrm{CF}$. This is the highest value reported in the open literature.

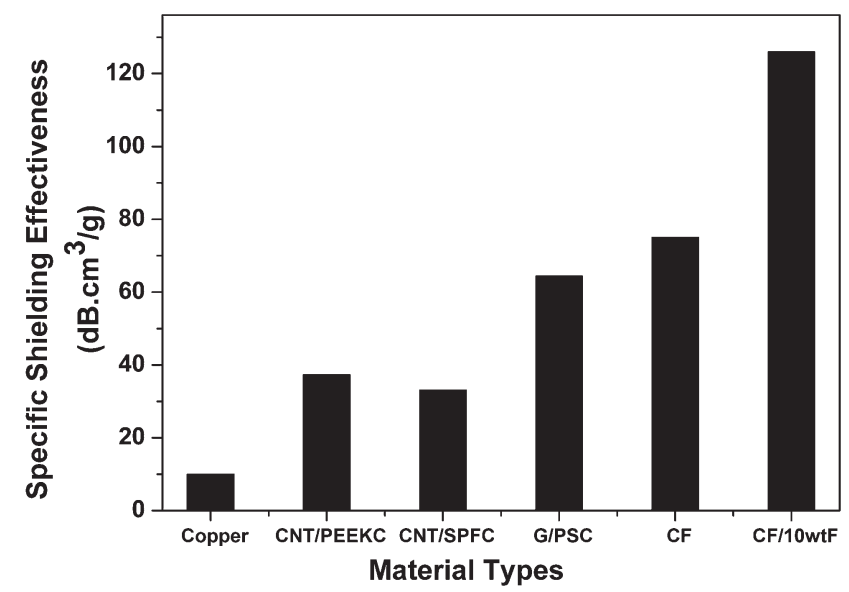

Fig. 6 Comparison of specific shielding effectiveness of different light weight materials (CNT/PEEKC: multi-walled carbon nanotube-poly(ether ether ketone) composite, ${ }^{5}$ CNT/SPFC: multi-walled carbon nanotube-polystyrene foam composites, $^{4}$ G/PCS: graphene polystyrene composites, ${ }^{24}$ CF: carbon foam without ferrocene, CF/10WF: carbon foam with 10 wt $\%$ ferrocene). 


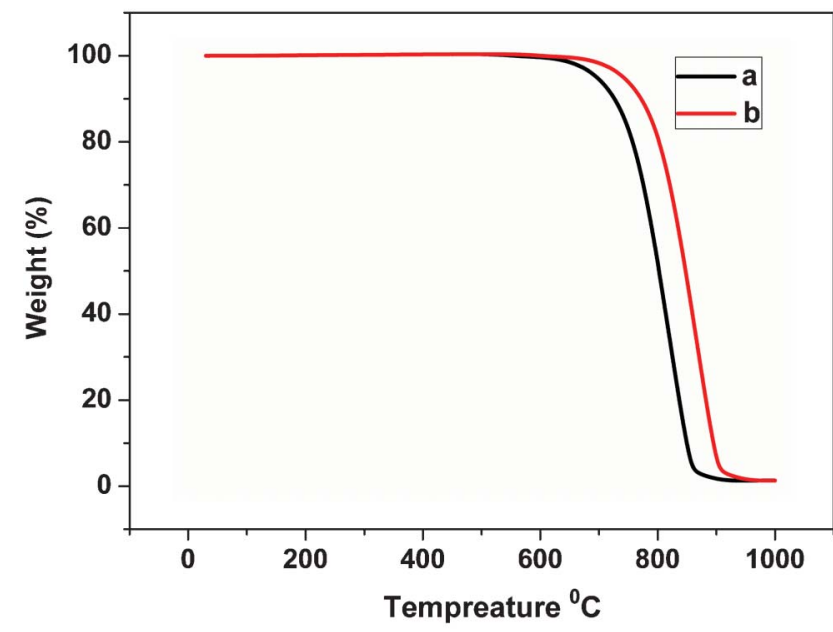

Fig. 7 TGA curve of carbon foam heat treated at $2500{ }^{\circ} \mathrm{C}$ (sample a, without ferrocene) and (sample b with $10 \mathrm{wt} \%$ of ferrocene, in oxidative environment).

The thermal stability of the CF is investigated by thermogravimetric analysis (TGA) in an oxidative (air) atmosphere. The thermal stability of CF depends upon the structure of carbon; the higher the graphitic structure of the carbon foam, the higher the thermal stability. ${ }^{25}$ It is observed that the thermal stability of sample b (with $10 \mathrm{wt} \%$ ferrocene loading) is superior to that of sample a (without ferrocene), as shown in Fig. 7. The thermal stability is higher by $\sim 50{ }^{\circ} \mathrm{C}$.

Sample a is thermally stable up to $560^{\circ} \mathrm{C}$; after that, weight loss initiated due to the oxidation of carbon. The major weight loss takes place between a temperature of 700 and $950{ }^{\circ} \mathrm{C}$ in both cases. The increase in the thermal stability of ferrocene added CF is due to the increase in the degree of graphitizability, in which the graphene layer alignment increases, and as a consequence, decreases the interlayer spacing.

\section{Conclusions}

The pitch based CF was developed from the sacrificial template technique with different weight fractions of nanosized ferrocene as a catalytic agent. It was found that, the ferrocene addition significantly influences the thermal and electrical conductivity, which had a positive effect on the electromagnetic shielding effectiveness of CF. The specific thermal conductivity and EMI shielding effectiveness increase from 92 to $121 \mathrm{~W} \mathrm{~cm}^{3} \mathrm{~g}^{-1} \mathrm{~m}^{-1}$ $\mathrm{K}^{-1}$ and 75 to $130 \mathrm{~dB} \mathrm{~cm} \mathrm{~g}^{-1}$. The thermal stability of $\mathrm{CF}$ increases by $50{ }^{\circ} \mathrm{C}$ in the oxidative atmosphere of $10 \mathrm{wt} \%$ ferrocene incorporated foam. This increment was due to the increase in degree of graphitizability of $\mathrm{CF}$ and as a result of catalytic graphitization. The light weight CF had a specific thermal conductivity and EMI shielding effectiveness which were higher than recently reported materials. Thus, light weight carbon foam is particularly suitable for civil and military aerospace industry.

\section{Acknowledgements}

The authors are highly grateful to Director, NPL, for his kind permission to publish the results. Thanks also to Mr. Jai Tawale for providing SEM characterization facilities. One of the authors (Rajeev Kumar) would like to thanks CSIR for an SRF fellowship.

\section{References}

1 P. Saini and M. Arora, Microwave Absorption and EMI Shielding Behavior of Nanocomposites Based on Intrinsically Conducting Polymers, Graphene and Carbon Nanotubes: In New Polymers for Special Applications by Gomes $A D$ (ed), Intech: Croatia, 2012, DOI: 10.5772/48779, Available from: http:// www.intechopen.com/download/pdf/38964.

2 J. N. Coleman, U. Khan, W. J. Blau and Y. K. Gun'ko, Small but strong: a review of the mechanical properties of carbon nanotube polymer composites, Carbon, 2006, 44(9), 1624-1652.

3 F. Du, Y. Ma, X. Lv, Y. Huang, F. Li and Y. Chen, The synthesis of single-walled carbon nanotubes with controlled length and bundle size using the electric arc method, Carbon, 2006, 44(7), 1327-1330.

4 Y. Yang, M. C. Gupta, K. L. Dudley and R. C. Lawrence, Novel carbon nanotube-polystryrene foam composites for electromagnetic interference shielding, Nano Lett., 2005, 5(11), 2131-2134.

5 H. Wang, G. Wang, W. Li, Q. Wang, W. Wei, Z. Jiang and S. Zhang, A material with electromagnetic radiation shielding effectiveness fabricated using multi-walled carbon nanotubes wrapped with poly(ether sulfone) in a poly(ether ether ketone) matrix, J. Mater. Chem., 2012, 22, 21232-21237.

6 J. Klett, R. Hardy, E. Romine, C. Walls and T. Burchell, High thermal conductivity, mesophase-pitch-derived carbon foams: effect of precursor on structure and properties, Carbon, 2000, 38, 953-973.

7 J. W. Klett, A. D. McMillan, N. G. Gallego, T. D. Burchell and C. A. Walls, Effect of heat treatment conditions on the thermal properties of mesophase pitch derived graphitic foams, Carbon, 2004, 42, 1849-1852.

8 N. C. Gallego and J. W. Klett, Carbon foams for thermal management, Carbon, 2003, 41(7), 1461-1466.

9 J. W. Klett, A. D.McMillan, N. C. Gallego and C. A. Walls, The role of structure on thermal properties of graphitic foams, $J$. Mater. Sci., 2004, 39(11), 3659-76.

10 M. Inagaki, T. Morishita, A. Kuno, T. Kito, M. Hirano and T. Suwa, et al., Carbon foams prepared from polyimide using urethane foam template, Carbon, 2004, 42(3), 497-502.

11 J. Yang, Z. M. Shen and Z. B. Hao, Microwave characteristics of sandwich composites with mesophase pitch carbon foams as core, Carbon, 2004, 42, 1882-85.

12 Z. Fang, X. Cao, C. Li, H. Zhang, J. Zhang and H. Zhang, Investigation of carbon foams as microwave absorber: numerical prediction and experimental validation, Carbon, 2006, 44(15), 3348-78.

13 Z. Fang, Z. C. Li, J. Sun, H. Zhang and J. Zhang, The electromagnetic characteristics of carbon foams, Carbon, 2007, 45(15), 2873-9.

14 F. Moglie, D. Micheli, S. Laurenzi, M. Marchetti and V. M. Primiani, Electromagnetic shielding performance of carbon foams, Carbon, 2012, 50, 1972-1980. 
15 A. Yadav, R. Kumar, G. Bhatia and G. L. Verma, Development of mesophase pitch derived high thermal conductivity graphite foam using a template method, Carbon, 2011, 49, 3622-3630.

16 P. Saini, V. Choudhary, K. N. Sood and S. K. Dhawan, Electromagnetic interference shielding behavior of polyaniline/graphite composites prepared by in situ emulsion pathway, J. Appl. Polym. Sci., 2009, 113, 3146-3155.

17 M. Braun and K. J. Huttinger, Sintering of powders of polyaromatic mesophase to high strength isotopic carbons: II Powders based on an iron catalyzed mesophase synthesis, Carbon, 1996, 34(12), 1473-1491.

18 M. Bernhauer, M. Braun and K. J. Huttinger, Kinetics of mesophase formation in a stirred tank reactor and properties of the products-V. Catalysis by ferrocene, Carbon, 1994, 32(6), 1073-1085.

19 S. R. Dhakate, R. B. Mathur and O. P. Bahl, Catalytic effect of iron oxide on carbon/carbon composite during graphitization, Carbon, 1997, 35, 1753-1756.

20 P. Saini, V. Choudhary, B. P. Singh, R. B. Mathur and S. K. Dhawan, Polyaniline-MWCNT nanocomposites for micro- wave absorption and EMI shielding, Mater. Chem. Phys., 2009, 113(2-3), 919-926.

21 P. Saini, V. Choudhary, B. P. Singh, R. B. Mathur and S. K. Dhawan, Enhanced microwave absorption behavior of polyaniline-CNT/polystyrene blend in $12.4-18.0 \mathrm{GHz}$ range, Synth. Met., 2011, 161(15-16), 1522-1526.

22 D. D. L Chung, Materials for electromagnetic shielding, J. Mater. Eng. Perform., 2000, 9, 350-354.

23 P. Saini, V. Choudhary, N. Vijayan and R. K. Kotnala, Improved electromagnetic interference shielding response of Poly(aniline)-coated fabrics containing dielectric and magnetic nanoparticles, J. Phys. Chem. C, 2012, 116(24), 13403-13412.

24 D. X. Yan, P. G. Ren, H. Pang, Q. Fu, M. B. Yang and Z. M. Li, Efficient electromagnetic interference shielding of light weight graphene polystyrene composite, J. Mater. Chem., 2012, 22, 18772-18774.

25 S. R. Dhakate, O. P. Bahl and P. D. Sahare, Oxidation Behaviour of PAN based carbon fiber reinforced phenolic resin matrix composites, J. Mater. Sci. Lett., 2000, 19(21), 1959-1961. 